\title{
AVALIAÇÃO DE GENÓTIPOS DE SORGO PARA RESISTÊNCIA AO Rhopalosiphum maidis (FITCH, 1856) (HEMIPTERA: APHIDIDAE) EM TESTE DE LIVRE ESCOLHA
}

\author{
ALYSSON RODRIGO FONSECA ${ }^{1}$, IVAN CRUZ² ${ }^{2}$ CÉSAR FREIRE CARVALHO ${ }^{3}$, BRÍGIDA SOUZA $^{3}$ \\ ${ }^{1}$ Engenheiro Agrônomo, Doutor em Entomologia, Divinópolis, $M G$ ) \\ ${ }^{2}$ Engenheiro Agrônomo, Doutor em Entomologia, Embrapa Milho e Sorgo, Sete Lagoas, MG ( autor para correspondência \\ ${ }^{3}$ Engenheiro Agrônomo, Doutor em Entomologia, UFLA, Lavras, MG
}

Revista Brasileira de Milho e Sorgo, v.5, n.1, p.26-36, 2006

\begin{abstract}
RESUMO - Para estudar aspectos relacionados à resistência de genótipos de sorgo ao pulgão Rhopalosiphum maidis (Fitch), foram conduzidos testes de livre escolha, na Embrapa Milho e Sorgo, em Sete Lagoas, MG, Brasil. Oito genótipos de sorgo, sendo sete de resistência conhecida ao pulgão Schizaphis graminum (Rondani) e o híbrido comercial BRS 303, foram semeados aleatoriamente, com distribuição circular, no espaçamento de $5 \mathrm{~cm}$ entre plantas, utilizando vasos de plástico com capacidade para 5 $\mathrm{kg}$ de solo. Após a emergência, as plantas foram cobertas por gaiolas cilíndricas, revestidas com "voil". Onze dias após o plantio, foram liberados, no centro de cada vaso, 45 pulgões adultos ápteros. Após 24, 48, 72 e 96 horas, o número de pulgões adultos por planta em cada genótipo foi registrado. Na última avaliação, contaram-se também as ninfas em cada planta. Posteriormente, o experimento foi repetido na ausência do genótipo BRS 303. Em ambos os ensaios, o delineamento experimental foi em blocos casualizados, com parcelas subdivididas, alocando-se nas parcelas os genótipos e, nas subparcelas, os períodos de exposição dos insetos. Considerando-se os resultados obtidos na presença e ausência do genótipo BRS 303, os genótipos TX 430 e TX 430 (GR) mostraram-se como os menos preferidos pelo pulgão $R$. maidis. No híbrido comercial BRS 303, foi onde se observou o maior número de pulgão, seguido pelo TX 2567.
\end{abstract}

Palavras-chave: Sorghum bicolor, pulgão-do-milho, comportamento, biologia.

\section{EVALUATION OF SORGHUM GENOTYPES FOR RESISTANCE TO Rhopalosiphum maidis (FITCH, 1856) (HEMIPTERA: APHIDIDAE) IN A FREE CHOICE TEST}

\begin{abstract}
Greenhouse trials, intended to evaluate the resistance of sorghum genotypes to Rhopalosiphum maidis (Fitch), were conducted in a free choice test, at the National Corn and Sorghum Research Center of EMBRAPA, in Sete Lagoas, MG, Brazil. Seven Sorghum genotypes known as resistant to Schizaphis graminum (Rondani) and a commercial cultivar BRS303 were randomly sowed in a circular distribution with 5 centimeters between plants, in plastic pots with capacity of $5 \mathrm{~kg}$. After emergence, the plants were covered with cylindrical cages, coated with "voil". Eleven days after planting, 45 wingless aphids were released at the center of each pot. After 24, 48, 72 and 96 hours, the number of adult aphids per plant was recorded on each genotype. The number of nymphs on each plant was also recorded at the last evaluation. After that, the experiment
\end{abstract}


was replicated with the absence of the genotype BRS303. In both trials, the experimental design was in randomized blocks, with split plots, allocating the genotypes in the plots and the insect exposed period in the subplots. The results obtained in the presence and absence of the genotype BRS303, the genotypes TX430 and TX430 (GR) were shown to be the less preferred to $R$. maidis. On the commercial hybrid BRS303 the greatest number of aphid was observed, followed by TX2567.

Key words: Sorghum bicolor, corn leaf aphid, behavior, biology

O pulgão Rhopalosiphum maidis (Fitch, 1856) ocorre em vários cultivos de importância econômica, como sorgo, milho, cana-de-açúcar, trigo, aveia, centeio, cevada e painço, além de também sobreviver em gramíneas silvestres (McColloch, 1921; Haves, 1922; Jackson et al., 1970; Foolt, 1977; Lamborot \& Guerreiro, 1979; Bing et al., 1992; Robison, 1992; Jauset et al., 1998).

Em sorgo, o pulgão geralmente infesta o cartucho e a panícula, sugando a seiva da planta. As folhas atacadas ficam cloróticas, encarquilhadas e enroladas, com manchas marrom-amareladas, recobertas por "honeydew". Sobre esses excrementos e seiva extravasada, desenvolve-se um fungo de cor preta, a fumagina, o qual, revestindo o limbo foliar, prejudica a atividade fotossintética (Haves, 1922; Waquil et al., 1986; Gahukar, 1993).

Além do dano direto à planta hospedeira pela sucção de seiva, segundo McColloch (1921) e Cartier \& Painter (1956), ataques intensos podem também afetar a qualidade e o poder germinativo das sementes, reduzindo seu valor comercial. $\mathrm{O}$ inseto é também vetor de várias doenças, incluindo mais de quinze causadas por vírus (Chan et al., 1991; Stoetzel \& Miller, 2001) como o mosaico anão em milho, sorgo e canade-açúcar (Sánchez et al., 1993) e o mosaico comum, considerada entre as mais importantes na cultura do milho, no Brasil, devido ao aumento em sua incidência e às perdas que pode causar na produção (Waquil et al., 1996; Dudienas et al. 1997; Oliveira et al., 1997). Segundo Edwardson \& Christie, (1991), o pulgão $R$. maidis é considerado a principal espécie transmissora da doença, em virtude da eficiência da transmissão. Estimativas de perdas em rendimento devido ao ataque dessa praga já foram relatadas na literatura internacional (Chillar \& Verna, 1982, Salem et al., 1986, Abdel Rahim et al., 1992, Ismail et al., 1993, Mansour et al., 1994, Al-Eryan \& El-Tabbakh, 2004). Os resultados obtidos por Al-Eryan \& El-Tabbakh (2004) indicaram que infestações de 818 pulgões por planta de milho, entre o estádio de desenvolvimento de dez folhas de milho até o pendoamento, causaram perdas em rendimento ao redor de $28 \%$. Aspectos da biologia da praga foram recentemente relatados no Brasil, em milho (Maia et al., 2004) e em sorgo (Fonseca et al., 2003).

Dentre os métodos de controle dessa praga, a resistência de plantas apresenta vantagens em relação a outros métodos de supressão, principalmente por reduzir suas populações a níveis que não causam danos, apresentando efeito cumulativo, persistente e não poluente, não acarretando ônus ao custo de produção e, finalmente, não exigindo conhecimentos específicos, por parte dos agricultores, para a sua utilização (Tingey, 1986; Vendramim, 1990; Lara, 1991). A resistência se baseia na capacidade de uma planta possuir meios para resistir ou tolerar o ata- 
que de uma determinada praga, sendo esses meios denominados "mecanismos de resistência" (Lara, 1991).

Estudos sobre a resistência de sorgo em relação à espécie de pulgão Schizaphis graminum foram conduzidos por Cruz (1986). Entre cerca de mil genótipos de sorgo, foram identificadas 28 fontes de resistência ao inseto, que exibem um ou mais mecanismos de resistência (não-preferência, antibiose ou tolerância), conforme descrito em Cruz \& Vendramim (1989abc, 1995ab, 1998a) e Cruz et al. (1998). Utilizando essas fontes de resistência, Fonseca et al. (2004) verificaram que o genótipo GR 1.1.1.1.1, que apresenta o mecanismo de tolerância a $S$. graminum também foi tolerante a $R$. maidis. Por outro lado, os genótipos TX 430 e GB 3, ao contrário, foram os mais suscetíveis ao pulgão do milho, com base no crescimento percentual e produção de biomassa.

Dando sequiência às pesquisas com a espécie $R$. maidis, esse trabalho objetivou estudar a resistência do tipo não-preferência, naqueles genótipos de sorgo relatados como resistentes ao pulgão Schizaphis graminum (Rondani, 1852), como descrito por Cruz (1986).

\section{Material e Métodos}

Os ensaios foram conduzidos em casa de vegetação, na Embrapa Milho e Sorgo em Sete Lagoas, MG. Foram testados os genótipos BRS 303, GB 3, GR1.1.1.1.1, GSBTX 399, IS 2293, TX 2567, TX 430 (GR) e TX 430 (IS 2536 x SC 170), sendo o primeiro, um híbrido comercial e os demais, resistentes ao pulgão Schizaphis graminum (Rondani, 1852), como determinado por Cruz (1986).

A metodologia empregada foi aquela descrita por Teetes et al. (1974) e adaptada por Cruz
(1986). Os genótipos foram semeados aleatoriamente, numa disposição circular, em vasos de 20 $\mathrm{cm}$ de diâmetro e $25 \mathrm{~cm}$ de altura. Utilizaram-se $5 \mathrm{~kg}$ de solo, adubado com a fórmula NPK 08$28-16+\mathrm{Zn}$, na quantidade de $3 \mathrm{~kg} / 1000 \mathrm{~kg}$ de solo, mantendo-se uma planta de cada genótipo por vaso, espaçadas entre si cerca de cinco centímetros. Cada vaso foi coberto por uma gaiola cilíndrica, feita com armação de arame, de aproximadamente $20 \mathrm{~cm}$ de diâmetro e $40 \mathrm{~cm}$ de altura, revestida por um tecido fino ("vuol"). Onze dias após o plantio, foram liberados, no centro de cada vaso, 45 pulgões adultos e ápteros. As avaliações relativas ao número de pulgões adultos por planta foram efetuadas após 24, 48, 72 e 96 horas das infestações. Inicialmente, foram testados os oito genótipos, e, posteriormente, o ensaio foi repetido na ausência do mais suscetível, o BRS 303. Após a última avaliação, as plantas, em ambos os experimentos, foram cortadas rente ao solo, individualizadas em sacos de plástico e levadas para o laboratório, onde se procedeu à contagem das ninfas.

Visando verificar a aleatoriedade da distribuição dos pulgões liberados no centro de cada vaso e a possível interferência externa sobre a atratividade dos pulgões para determinado genótipo, nos diferentes intervalos de avaliação, efetuou-se um ensaio preliminar, utilizando-se somente o genótipo BR 303, suscetível ao pulgão $R$. maidis, com nove plantas por vaso e dez repetições. O número de afídeos liberados, bem como os intervalos de avaliação, foram os mesmos utilizados nos experimentos descritos anteriormente.

A temperatura e a umidade relativa do ar foram registradas por um termohigrógrafo colocado próximo ao experimento e em local protegido da incidência direta de raios solares. As determinações médias diárias desses dois fatores 
foram feitas empregando-se a metodologia citada em Climanálise (1998). O fotoperíodo não foi controlado; entretanto, segundo o Setor de Climatologia da Embrapa Milho e Sorgo, na época e local dos estudos, foi de 14 horas de luz.

O delineamento experimental foi em blocos casualizados, em parcelas subdivididas, alocando-se os genótipos nas parcelas e os períodos de avaliação nas subparcelas, com 20 repetições. Os dados foram transformados para raiz quadrada de $(x+0,1)$ antes de se proceder à análise de variância, seguida do teste de agrupamento de médias de Scott e Knott, a 5\% de probabilidade (Scott \& Knott, 1974).

\section{Resultados e Discussão}

O número de pulgões encontrados em cada planta, no ensaio preliminar, não diferiu significativamente pela análise de variância, tanto para os intervalos de tempo quanto para as posições das plantas no vaso, em relação ao ambiente externo (Tabela 1). Esses resultados mostram que houve uma distribuição uniforme dos pulgões em cada planta, independente da sua posição no vaso, indicando tratar-se de uma metodologia adequada para os testes de livre escolha com $R$. maidis em genótipos de sorgo.

TABELA 1. Número de adultos $( \pm \text { EP })^{1}$ de Rhopalosiphum maidis por planta de sorgo, cultivar BR 303, em função do tempo de liberação, em casa de vegetação, sob a temperatura de $24,1 \pm 9,3{ }^{\circ} \mathrm{C}$ e UR $82 \pm 14 \%$.

\begin{tabular}{ccccc}
\hline \multirow{4}{*}{$\begin{array}{c}\text { Posição da } \\
\text { planta no vaso }\end{array}$} & \multicolumn{4}{c}{ Período de avaliação (horas) } \\
\cline { 2 - 5 } & $\mathbf{2 4}$ & $\mathbf{4 8}$ & $\mathbf{7 2}$ & $\mathbf{9 6}$ \\
\hline 1 & $2,7 \pm 0,55$ & $4,0 \pm 0,60$ & $4,1 \pm 0,51$ & $4,2 \pm 0,53$ \\
3 & $4,5 \pm 0,92$ & $4,2 \pm 0,76$ & $4,2 \pm 0,67$ & $4,2 \pm 0,78$ \\
4 & $4,1 \pm 0,61$ & $4,8 \pm 0,79$ & $4,7 \pm 0,54$ & $4,6 \pm 0,49$ \\
5 & $4,3 \pm 0,57$ & $4,3 \pm 0,80$ & $4,4 \pm 0,72$ & $4,7 \pm 0,50$ \\
6 & $2,8 \pm 0,49$ & $3,1 \pm 0,61$ & $3,2 \pm 0,54$ & $3,7 \pm 0,45$ \\
7 & $3,7 \pm 0,84$ & $3,5 \pm 0,83$ & $3,6 \pm 0,63$ & $3,7 \pm 0,67$ \\
8 & $4,5 \pm 0,64$ & $4,3 \pm 0,52$ & $3,9 \pm 0,46$ & $3,9 \pm 0,43$ \\
9 & $3,6 \pm 0,63$ & $5,2 \pm 0,61$ & $5,1 \pm 0,63$ & $5,1 \pm 0,66$ \\
Total & $3,4 \pm 0,78$ & $4,1 \pm 0,62$ & $4,1 \pm 0,54$ & $4,1 \pm 0,52$ \\
\hline Média & 33,6 & 37,5 & 37,3 & 38,2 \\
\hline
\end{tabular}

${ }^{1}$ Valores não significativos pela análise de variância, para tempo e posição.

No ensaio preliminar, envolvendo somente o genótipo BR 303, embora não tenha sido detectada diferença significativa entre os períodos de avaliação, de maneira geral, um menor número de pulgões foi constatado 24 horas após a liberação, com média de 3,7 indivíduos, mostrando que os insetos ainda não se haviam esta- belecido nos hospedeiros. A partir de 48 horas, o número de pulgões manteve-se estável, com uma média de 4,2 insetos, correspondendo a $84 \%$ do total liberado.

No que concerne ao experimento envolvendo os oito genótipos (Tabela 2), 24 horas após a liberação, observou-se um número médio de 
4,8 pulgões por planta, independente do material genético utilizado, mostrando que $96 \%$ dos afídeos já se encontravam sobre os hospedeiros. Esse número se reduziu progressivamente nas avaliações posteriores, provavelmente pelo fato de os insetos se deslocarem das plantas, através do solo, em busca de hospedeiros mais adequados.

Após 24 horas, os genótipos BRS 303, IS 2293 e GB 3 foram os mais preferidos; GR 1.1.1.1.1 e GSBTX 399 mostraram resultados intermediários, ficando TX 2567; TX 430 e TX 430 (GR) como os menos preferidos pelos pulgões. Após 48 horas, os resultados foram semelhantes; entretanto, o genótipo GSBTX 399 passou a ser incluído no grupo das plantas mais preferidas. $\mathrm{Na}$ avaliação realizada após 72 horas, apenas os genótipos BRS 303 e IS 2293 diferiram significativamente como mais preferidos. Finalmente, após 96 horas, observou-se que o BRS 303 apresentou número significativamente maior de pulgões, seguido pelos genótipos GR 1.1.1.1.1, IS 2293, GSBTX 399 e TX 2567, que apresentaram núme- ros intermediários. Os genótipos menos preferidos foram o GB 3, TX 430 e TX 430 (GR), sendo que os dois últimos mantiveram, durante todo o período de avaliação, um número de pulgões abaixo da média geral e não foram significativamente diferentes entre si (Tabela 2).

Segundo Norris \& Kogan (1980), Corcuera (1984) e Rustamani et al. (1992), metabólitos secundários de plantas, tais como os alcalóides e o ácido aconítico, podem estar presentes em cultivares de sorgo, causando deterrência em afídeos e, dessa forma, proporcionando à planta resistência a esses insetos. Dreyer \& Cambell (1984) mostraram que a resistência do sorgo a pulgões pode estar, ainda, associada a fatores físicos, tal como o grau de metilação da pectina na matriz intercelular. A natureza estrutural dessa pectina, que funciona nas plantas como um cimento intercelular, pode dificultar a penetração dos estiletes do inseto em direção ao floema e, dessa forma, a cultivar pode se tornar menos preferida pelo pulgão.

TABELA 2. Número de adultos $( \pm \mathrm{EP})^{1}$ de Rhopalosiphum maidis por planta de sorgo, em função do genótipo e do tempo de exposição, em casa de vegetação, sob temperatura de $25,6 \pm 8,4{ }^{\circ} \mathrm{C}$ e UR $82 \pm 13 \%$.

\begin{tabular}{lcccc}
\hline \multirow{2}{*}{ Genótipos } & \multicolumn{4}{c}{ Período de avaliação (horas) } \\
\cline { 2 - 5 } & $\mathbf{2 4}$ & $\mathbf{4 8}$ & $\mathbf{7 2}$ & $\mathbf{9 6}$ \\
\hline BRS 303 & $7,1 \pm 1,11 \mathrm{a}$ & $6,3 \pm 0,93 \mathrm{a}$ & $6,8 \pm 0,81 \mathrm{a}$ & $6,3 \pm 0,64 \mathrm{a}$ \\
GR 1.1.1.1.1 & $4,4 \pm 0,85 \mathrm{~b}$ & $4,1 \pm 0,71 \mathrm{~b}$ & $4,2 \pm 0,54 \mathrm{~b}$ & $4,4 \pm 0,52 \mathrm{~b}$ \\
IS 2293 & $5,5 \pm 1,14 \mathrm{a}$ & $5,5 \pm 1,14 \mathrm{a}$ & $5,6 \pm 0,82 \mathrm{a}$ & $4,2 \pm 0,49 \mathrm{~b}$ \\
GSB TX 399 & $5,2 \pm 1,16 \mathrm{~b}$ & $4,9 \pm 1,07 \mathrm{a}$ & $4,4 \pm 0,87 \mathrm{~b}$ & $3,7 \pm 0,43 \mathrm{~b}$ \\
TX 2567 & $3,2 \pm 0,64 \mathrm{c}$ & $3,0 \pm 0,58 \mathrm{~b}$ & $3,7 \pm 0,48 \mathrm{~b}$ & $3,5 \pm 0,33 \mathrm{~b}$ \\
GB 3 & $6,6 \pm 1,39 \mathrm{a}$ & $5,8 \pm 1,15 \mathrm{a}$ & $4,3 \pm 0,73 \mathrm{~b}$ & $2,9 \pm 0,41 \mathrm{c}$ \\
TX 430 & $3,4 \pm 0,91 \mathrm{c}$ & $3,9 \pm 0,98 \mathrm{~b}$ & $3,3 \pm 0,67 \mathrm{~b}$ & $2,3 \pm 0,47 \mathrm{c}$ \\
TX 430 (GR) & $3,2 \pm 0,51 \mathrm{c}$ & $2,9 \pm 0,58 \mathrm{~b}$ & $2,7 \pm 0,42 \mathrm{~b}$ & $1,8 \pm 0,39 \mathrm{c}$ \\
\hline \multicolumn{1}{c}{ Total } & 38,6 & 36,4 & 35,0 & 29,1 \\
\hline \multicolumn{1}{c}{ Média } & 4,8 & 4,5 & 4,4 & 3,6 \\
\hline
\end{tabular}

${ }^{1}$ Erro padrão

Médias seguidas pelas mesmas letras, nas colunas, não diferem significativamente entre si, pelo teste de Scott e Knott, a $5 \%$ de probabilidade. 
Com relação à produção de ninfas, os genótipos BRS 303, GSBTX 399, IS 2293 e GR 1.1.1.1.1 mostraram um número significativamente maior em relação aos demais (Tabela 3). Considerando o número de pulgões adultos na avaliação realizada após 96 horas (Tabela 2), verificou-se que os genótipos GB 3, TX 430 e TX 430 (GR) foram os menos preferidos pelos pulgões, havendo, portanto, uma confirmação dos resultados. Isso ocorreu, provavelmente, devido ao fato de um menor número de insetos gerar menor descendência e, ainda, pela presença de metabólitos secundários na planta, que podem afetar a produção e a sobrevivência de ninfas, conforme relatado por Corcuera (1984).

$\mathrm{Na}$ ausência do genótipo BRS 303, suscetível ao pulgão (Tabela 4), constatou-se, após
24 e 48 horas da liberação, uma média de 4,4 insetos por planta, independente do genótipo, mostrando que $88 \%$ dos afídeos já se encontravam sobre os hospedeiros. Nas demais avaliações, houve uma redução gradativa no número de insetos, atingindo um mínimo com 96 horas, com uma média de 3,9 pulgões. Essa redução ocorreu, provavelmente, devido ao fato de alguns genótipos não serem preferidos pelos pulgões, os quais podem ter-se deslocado em busca de outro hospedeiro, ficando sob a terra do vaso ou nas paredes da gaiola.

Com relação à discriminação dos genótipos pelos pulgões, nas avaliações realizadas com 24 e 48 horas, observou-se que o TX 2567 e o IS 2293 mostraram ser significativamente mais preferidos pelos pulgões em relação aos

TABELA 3. Número de ninfas $( \pm \mathrm{EP})^{1}$ de Rhopalosiphum maidis em genótipos de sorgo, após 96 horas da liberação de adultos, em casa de vegetação, sob temperatura de $25,6 \pm 8,4{ }^{\circ} \mathrm{C}$ e UR $82 \pm 13 \%$.

\begin{tabular}{lc}
\hline Genótipos & Número ninfas/planta $^{\mathbf{3}}$ \\
\hline BRS 303 & $39,5 \pm 4,11 \mathrm{a}$ \\
GSBT X399 & $35,3 \pm 4,66 \mathrm{a}$ \\
IS 2293 & $28,1 \pm 2,98 \mathrm{a}$ \\
GR 1.1.1.1.1 & $28,0 \pm 2,63 \mathrm{a}$ \\
GB 3 & $23,3 \pm 3,34 \mathrm{~b}$ \\
TX 2567 & $21,6 \pm 2,86 \mathrm{~b}$ \\
TX 430 & $21,4 \pm 2,17 \mathrm{~b}$ \\
TX 430 (GR) & $15,9 \pm 2,43 \mathrm{~b}$ \\
\hline CV $(\%)^{2}$ & 27,0 \\
\hline
\end{tabular}

${ }^{1}$ Erro padrão

${ }^{2}$ Coeficiente de variação

${ }^{3}$ Médias seguidas pelas mesmas letras não diferem significativamente entre si, pelo teste de Scott e Knott, a $5 \%$ de probabilidade.

demais, com densidades médias de 6,8 e 5,5 pulgões, respectivamente. A avaliação após 72 horas mostrou resultados semelhantes aos obtidos nas anteriores, com exceção do IS 2293, que passou a integrar o grupo dos genótipos menos preferidos. Na última avaliação, os genótipos TX 430 
(GR) e TX 430 foram os menos preferidos, com médias de 2,8 e 2,6 pulgões, respectivamente. Em posição intermediária, ficaram os genótipos GR 1.1.1.1.1, GB 3 e GSBTX 399, seguido pelo IS 2293. O TX 2567 foi o mais atrativo a $R$. maidis, com média de 6,0 pulgões, apresentando cerca de 2,2 vezes mais indivíduos que os genótipos TX 430 (GR) e TX 430, tidos como os menos preferidos pelo inseto (Tabela 4).

TABELA 4. Número de adultos $( \pm \mathrm{EP})^{1,2}$ de Rhopalosiphum maidis por planta de sorgo, em função do genótipo e do tempo de exposição, na ausência do genótipo BRS 303, em casa de vegetação, sob temperatura de $26,4 \pm 9,7^{\circ} \mathrm{C}$ e UR $85 \pm 11 \%$.

\begin{tabular}{lcccc}
\hline \multirow{2}{*}{ Genótipos } & \multicolumn{4}{c}{ Período de avaliação (horas) } \\
\cline { 2 - 5 } & $\mathbf{2 4}$ & $\mathbf{4 8}$ & $\mathbf{7 2}$ & $\mathbf{9 6}$ \\
\hline TX 2567 & $6,7 \pm 1,04 \mathrm{a}$ & $6,9 \pm 0,92 \mathrm{a}$ & $6,5 \pm 0,88 \mathrm{a}$ & $6,0 \pm 0,58 \mathrm{a}$ \\
IS 2293 & $5,5 \pm 1,01 \mathrm{a}$ & $5,5 \pm 1,06 \mathrm{a}$ & $4,4 \pm 0,70 \mathrm{~b}$ & $4,5 \pm 0,64 \mathrm{~b}$ \\
GR 1.1.1.1.1 & $4,3 \pm 0,92 \mathrm{~b}$ & $4,6 \pm 0,98 \mathrm{~b}$ & $4,3 \pm 0,75 \mathrm{~b}$ & $4,2 \pm 0,65 \mathrm{c}$ \\
GB 3 & $3,1 \pm 0,65 \mathrm{~b}$ & $3,6 \pm 0,60 \mathrm{~b}$ & $3,6 \pm 0,63 \mathrm{~b}$ & $3,8 \pm 0,46 \mathrm{c}$ \\
GSB TX 399 & $4,7 \pm 0,93 \mathrm{~b}$ & $4,2 \pm 0,76 \mathrm{~b}$ & $4,1 \pm 0,64 \mathrm{~b}$ & $3,5 \pm 0,58 \mathrm{c}$ \\
TX 430 (GR) & $3,1 \pm 0,75 \mathrm{~b}$ & $2,8 \pm 0,67 \mathrm{~b}$ & $2,8 \pm 0,55 \mathrm{~b}$ & $2,8 \pm 0,48 \mathrm{~d}$ \\
TX 430 & $3,5 \pm 0,88 \mathrm{~b}$ & $3,6 \pm 0,83 \mathrm{~b}$ & $3,2 \pm 0,57 \mathrm{~b}$ & $2,6 \pm 0,41 \mathrm{~d}$ \\
\hline Total & 31,0 & 31,2 & 28,9 & 27,4 \\
\hline Média & 4,4 & 4,4 & 4,1 & 3,9
\end{tabular}

${ }^{1}$ Erro padrão

${ }^{2}$ Médias seguidas pelas mesmas letras, nas colunas, não diferem significativamente entre si, pelo teste de Scott e Knott, a $5 \%$ de probabilidade.

Esses resultados foram semelhantes aos obtidos quando o genótipo suscetível BRS 303 estava presente (Tabela 2), quando o TX 430 (GR) e o TX 430 também se mostraram como os menos preferidos pelo inseto.

Cruz (1986), avaliando a resistência de genótipos de sorgo ao pulgão $S$. graminum, observou que o GSBTX 399, GR 1.1.1.1.1, TX 430 (GR) e GB 3 foram os menos preferidos pelo pulgão, sendo esses resultados semelhantes aos obtidos neste trabalho. Assim, as causas que poderiam estar conferindo ao sorgo resistência a $S$. graminum poderiam estar atuando de maneira análoga em relação a $R$. maidis, embora alguns genótipos tidos como não-preferidos ao pulgão $R$. maidis tenham se mostrado suscetíveis a $S$. graminum.
O genótipo TX 2567 diferiu significativamente dos demais, apresentando o maior número de ninfas por planta (Tabela 5). Esses resultados são semelhantes aos apresentados na Tabela 4, na qual ficou evidenciada a maior atratividade desse material em relação ao pulgão, sendo de se esperar um maior número de ninfas nessa cultivar. De forma semelhante, os genótipos previamente determinados como menos preferidos (Tabela 4) foram os que apresentaram os menores números de ninfas (Tabela 5).

Considerando as avaliações realizadas na presença e ausência do genótipo BRS 303, o mecanismo de não-preferência foi evidenciado principalmente nos genótipos TX 430 e TX 430 (GR), os quais mostraram-se menos preferidos 
TABELA 5. Número de ninfas $( \pm E P)^{1}$ de Rhopalosiphum maidis em genótipos de sorgo, após 96 horas da liberação de adultos, na ausência do genótipo BRS 303, em casa de vegetação, sob temperatura de $26,4 \pm 9,7{ }^{\circ} \mathrm{C}$ e UR $85 \pm 11 \%$.

\begin{tabular}{lc}
\hline Genótipos & Número ninfas/planta $^{\mathbf{3}}$ \\
\hline TX 2567 & $64,5 \pm 5,54 \mathrm{a}$ \\
GR 1.1.1.1.1 & $44,8 \pm 6,56 \mathrm{~b}$ \\
GSBTX 399 & $42,6 \pm 4,58 \mathrm{~b}$ \\
IS 2293 & $38,7 \pm 6,11 \mathrm{~b}$ \\
GB 3 & $34,4 \pm 5,42 \mathrm{~b}$ \\
TX 430 & $33,2 \pm 4,33 \mathrm{~b}$ \\
TX 430 (GR) & $30,4 \pm 3,52 \mathrm{~b}$ \\
\hline CV $(\%)^{2}$ & 30,8 \\
\hline
\end{tabular}

${ }^{1}$ Erro padrão

${ }^{2}$ Coeficiente de variação

${ }^{3}$ Médias seguidas pelas mesmas letras não diferem significativamente entre si, pelo teste de Scott e Knott, a 5\% de probabilidade.

em todos os testes realizados. O BRS 303 foi o que exerceu maior atratividade sobre o inseto, sendo que, na sua ausência, o mais preferido foi o TX 2567, seguido pelo IS 2293. A linhagem TX 430 (GR) é o resultado do cruzamento entre TX 430 x GR 1-1-1, sendo a linhagem GR 1-11 - a fonte de resistência ao pulgão-verde, $S$. graminum e TX 430 a linhagem comercial suscetível a essa espécie. Comparando os dados apresentados neste trabalho, nota-se que a linhagem TX 430 não diferiu significativamente de TX 430 x GR 1-1-1, quanto ao número de pulgões ou ninfas. Por outro lado, a linhagem GR 1-1-1-1 sempre diferiu significativamente da TX 430 e da TX 430 x GR 1-1-1. Portanto, a linhagem que detém o(s) gene (s) de resistência ao pulgão-domilho é a TX 430 e não GR 1-1-1.

\section{Conclusões}

O mecanismo de resistência por não-preferência foi detectado no genótipo TX 430, o qual poderá ser utilizado em programas de melhoramento visando à resistência do sorgo ao pulgão R. maidis.

\section{Literatura Citada}

ABDEL RAHIM, M. M.; ABDEL FATTAH, M. I.; FA RAG, A. I.; EL-NAGGAR, M.A.Z. Contribution to the study of the corn leaf aphids Rhopalosiphum maidis Fitch, on maize plants. Bulletin of the Entomological Society of Egypt, Cairo, v. 70, p. 91-98, 1992.

AL-ERYAN, M. A. S.; EL-TABBAKH, S. Sh. Forecasting yield of corn, Zea mays infested with corn leaf aphid, Rhopalosiphum maidis. Journal of Applied Entomology, Hamburg, v. 128, n. 4, p. 312-315, 2004.

BING, J. W.; GUTHIRIE, W. D.; DICKE, F. F. Genetics of resistance in maize to the corn leaf aphid (Homoptera: Aphididae). Journal of Economic Entomology, College Park, v. 85, n. 4, p. 1476-1479, 1992.

CHAN, C. K.; FORBES, A. R.; RAWORTH, D. A. Aphid-transmitted viruses and their vectors of the world. Vancouver: Agriculture Canada, 1991. 216 p. (Canada Research Branch Technical Bulletin, 3E)

CHILLAR, B. S.; VERMA, A.N. Yield losses caused by the aphid Rhopalosiphum maidis Fitch in different varieties strains of barley crop. Haryana Agriculture University Journal Research, Hisar, v. 12, p. 298-300, 1982.

CLIMANÁLISE: Boletim de Monitoramento e Análise Climática. Cachoeira Paulista, v. 13, n. 6, p. 45, 1998.

CORCUERA, L. J. Effects of indole alkaloids from gramineae on aphids. Phytochemistry, Elmsford, v. 23, n. 3, p. 539-541, 1984. 
CRUZ, I. Resistência de genótipos de sorgo ao pulgão-verde Schizaphis gramimun (Rondani, 1852) (Homoptera: Aphididae). 1986. 222 p. Tese (Doutorado em Entomologia) - Escola Superior de Agricultura Luiz de Queiroz, Universidade de São Paulo, Piracicaba.

CRUZ, I.; VENDRAMIM, J. D. Biologia do pulgão-verde em diferentes hospedeiros. Pesquisa Agropecuária Brasileira, Brasília, DF, v. 24, n. 3, p. 277-282, 1989a.

CRUZ, I.; VENDRAMIM, J. D. Biologia do pulgão-verde em sorgo. Pesquisa Agropecuária Brasileira, Brasília, DF, v. 24, n. 3, p. 283-289, 1989 b.

CRUZ, I.; VENDRAMIM, J. D. Efeito de diferentes genótipos de sorgo resistentes no desempenho do pulgão-verde Schizaphis graminum Rond.. Anais da Sociedade Entomológica do Brasil, Jaboticabal, v. 24, n. 2, p. 253-257, 1995a.

CRUZ, I.; VENDRAMIM, J. D. Herança da resistência de sorgo ao pulgão-verde, Schizaphis graminum (Rond.) (Homoptera: Aphididae). Anais da Sociedade Entomológica do Brasil, Jaboticabal, v. 24, n. 3, p. 429-436, 1995 b.

CRUZ, I.; VENDRAMIM, J. D. Não-preferência como mecanismo de resistência sorgo ao pulgão-verde. Pesquisa Agropecuária Brasileira, Brasília, DF, v. 24, n. 3, p. 329-335, 1989c.

CRUZ, I.; VENDRAMIM, J. D. Tolerância como mecanismo de resistência de sorgo ao pulgãoverde, Schizaphis graminum (Rond) (Homoptera: Aphididae). Anais da Sociedade Entomológica do Brasil, Jaboticabal, v. 27, n. 1, p. 141-148, 1998.

CRUZ, I.; VENDRAMIM, J. D.; OLIVEIRA, A. C. Determinação do período de avaliação de nãopreferência de sorgo ao pulgão-verde, Schizaphis graminum (Rond.) (Homoptera: Aphididae); Anais da Sociedade Entomológica do Brasil, Jaboticabal, v. 27, n. 2, p. 383-386, 1998.

DREYER, D. L.; CAMPBELL, B. C. Association of the degree of methylation of intercellular pectin with plant resistance to aphids and with induction of aphid biotypes, Experientia, Viçosa, v. 40, n. 2, p. 224-226, 1984.

DUDIENAS, C.; DUARTE, A. P.; PATERNIANI, M. E. A. G. Z.; RIBEIRO, J. L.; BIANCHINI, M. T.; KANTHACH, R. A. D.; CASTRO, J. L.; SILVEIRA, L. C. P.; DENUCCI, S.; JUNIOR, J. S.; BOLONHESI, D.; DE SORDI, G. Severidade de doenças no milho "safrinha" no Estado de São Paulo em 1996. In: SEMINÁRIO SOBRE A CULTURA DO MILHO "SAFRINHA", 4., 1997, Assis. Anais... Campinas: IAC/CDV, 1997. p.107-115. Coordenado por Aildson Pereira Duarte.

EDWARDSON, J. R.; CHRISTIE, R.G. The potyvirus group. Volumes 1-4, Florida Agricultural Experiment Station, Monograph 16, 1991.

FONSECA, A. R.; CARVALHO, C. F.; SOUZA, B.; CRUZ, I. Desenvolvimento de Rhopalosiphum maidis (Fitch, 1856) (Hemiptera: Aphididae) em sorgo, cultivar BR304. Ciência e Agrotecnologia, Lavras, MG, Edição especial, p. 1470-1478, 2003.

FONSECA, A. R.; CRUZ, I.; CARVALHO, C. F.; SOUZA, B. Resistência de genótipos de sorgo ao pulgão Rhopalosiphum maidis (Fitch, 1856) (Hemiptera:Aphididae): III efeito no desenvolvimento da planta. Ciência e Agrotecnologia, Lavras, MG, v. 28, n. 3, p. 585-592, 2004.

FOOLT, W. H. Biology of corn leaf aphid, Rhopalosiphum maidis (Homoptera: Aphididae), 
in Southwestern Ontario. The Canadian Entomologist, Ottawa, v. 109, p. 1129-1135, 1977.

HAVES, W. P. Observations on insects attacking sorghums. Journal of Economic Entomology, College Park, v. 15, p. 349-356, 1922.

ISMAIL, I. I.; SEMEADA, A. M.; EL-SALAM, A. Seasonal occurrence and hos rang of the corn leaf aphid Rhopalosiphum maidis Fitch at Giza and Qualubia Governorates. Bulletin of the Entomological Society of Egypt, Cairo, v. 71, p. 33-40, 1993.

JACKSON, H.B.; COLES, L.W.; WOOD, E.A.; EIKENBARY, R. D. Parasites reared from the greenbug and corn leaf aphid in Oklahoma in 1968 e 1969. Journal of Economic Entomology, College Park, v. 63, n. 3, p. 733-736, 1970.

JAUSET, A. M.; MUÑOZ, M. P.; PONS, X. Karyotypes of Rhopalosiphum maidis (Fitch) in the Lleida Basin. Integrated Control in Cereal Crops, Hannover, v. 21, n. 8, p. 15-20, 1998.

LAMBOROT, L. L.; GUERRERO, M. A. Dinamica poblacional de los afidos de cereales y sus enemigos naturales en la provincia de Santiago durante las temporadas 1976 y 1977. Investigacion Agricola, Santiago, v. 5, n. 1, p. 23-32, 1979.

LARA, F. M. Princípios de resistência de plantas a insetos. São Paulo: Ícone, 1991. 336 p.

MANSOUR, M. H.; SALEM, N. Y., AMR, E. M.; SALEM, H. A. Injury levels and yield loss model for the corn aphid, Rhopalosiphum maidis (Fitch) on corn, Zea mays (L.) Bulletin of the Entomological Society of Egypt, Cairo, v. 72, p. 217-227, 1994.

McCOLLOCH, J. W. The corn leaf aphis (Aphis maidis Fitch) in Kansas. Journal of Economic
Entomology, College Park, v. 14, n. 1, p. 8994, 1921.

MAIA, W. J. M. S.; CARVALHO, C. F.; CRUZ, I.; SOUZA, B.; FERREIRA MAIA, T. J. A. Influência da temperatura no desenvolvimento de Rhopalosiphum maidis (Fitch, 1856) (Hemiptera: Aphididae) em condições de laboratório. Ciência e Agrotecnologia, Lavras, MG, v. 28, n. 3, p. 520-529, 2004.

NORRIS, D. M.; KOGAN, M. Biochemical and morphological bases of resistance. In: FOWDEN, F. G.; JENNINGS, P. R. (Ed.). Breeding Plants Resistant to Insects. New York: J. Wiley, 1980. p. 23-61.

OLIVEIRA, E.; WAQUIL, J. M.; PINTO, N. F. J. A. Doenças causadas por patógenos transmitidos por insetos: complexo enfezamento/mosaico. In: SEMINÁRIO SOBRE A CULTURA Do Milho "Safrinha", 4., 1997, Assis. Anais... Campinas: IAC/CDV, 1997. p.87-94. Coordenado por Aildson Pereira Duarte

ROBINSON, J. Modes of resistance in barley seedlings to six aphid (Homoptera: Aphididae) species. Journal of Economics Entomology, College Park, v. 85, n. 6, p. 2510-2515, 1992.

RUSTAMANI, M. A.; KANEHISA, K.; TSUMUKI, H.; SHIRAGA, T. Further observation on the relationship between aconitic acid contents and aphid densities on some cereal plants. Bulletin of the Research Institute for Bioresources, Okayama, v. 1, n. 1, p. 9-20, 1992.

SALEM, S.A.; ZAKI, F.N.; HAMDY, M.K.; MOAWAD, S.M. Yield reduction caused by the corn aphid Rhopalosiphum maidis Fitch (Homoptera:Aphididae) in corn. Bulletin of the Entomological Society of Egypt - Econ. Ser., Cairo, v. 15, p. 65-71, 1986. 
SÁNCHEZ, M. del C., CERMELI, M., DEBROT, E. Epidemiologia del virus del mosaico enanizante del maiz (MDMV) en parcelas experimentales de sorgo Sorghum bicolor (L.) Moench. II. Eficiencia de transmision con afidos y dispersion del virus. Agronomía Tropical, Maracay, v. 43, n. 5-6, p. 227-240, 1993.

SCOTT, A. J.; KNOTT, M. A. A cluster analysis method for grouping means in the analysis of variance. Biometrics, Washington, v. 30, n. 3, p. 507-512, 1974.

STOETZEL, M. B.; MILLER, G. L. Aerial feeding aphids of corn in the United States with reference to the root-feeding Aphis maidiradicis (Homoptera: Aphididae). Florida Entomologist, Gainsville, v. 84, n. 1, p. 83-98, 2001

TEETES, G. L.; SCHAEFFER, C. A.; JOHNSON, D. T. Resistance in Sorghum to the greenbugs: laboratory determination of mechanisms of resistance. Journal of Economic Entomology, College Park, v. 67, n. 3, p. 393396, 1974.

TINGEY, W. M. Techniques for evaluating plant resistance to insects. In: MILLER, J. R.; MILLER, T. A. (Ed.) Insect-plant Interactions. New York: Springer-Verlag, 1986. p. 251-284.

VENDRAMIM, J. D. A resistência de plantas e o manejo de pragas. In: CROCOMO, W. B. (Ed.). Manejo integrado de pragas. São Paulo: UNESP, 1990. p. 177-197.

WAQUIL, J. M .; OLIVEIRA, E.; PINTO, N. F. J. A.; FERNANDES, F. T.; CORREIA, L. A. Viroses em milho, incidência e efeito na produção. Fitopatologia Brasileira, Brasília, DF, v. 21, p. $460-463,1996$.

WAQUIL, J. M.; CRUZ, I.; VIANA, P. A. Pragas do sorgo. Informe Agropecuário, Belo Horizonte, v. 12, n. 144, p. 46-51, 1986. 